\title{
Transcriptomic profiling of linolenic acid-responsive genes in ROS signaling from RNA-seq data in Arabidopsis
}

\section{Capilla Mata-Pérez ${ }^{1}$, Beatriz Sánchez-Calvo ${ }^{1}$, Juan C. Begara-Morales ${ }^{1}$, Francisco Luque ${ }^{2}$, Jaime Jiménez-Ruiz ${ }^{1}$, María N. Padilla ${ }^{1}$, Jesús Fierro-Risco ${ }^{1}$, Raquel Valderrama ${ }^{1}$, Ana Fernández-Ocaña ${ }^{1}$, Francisco J. Corpas ${ }^{3}$ and Juan B. Barroso ${ }^{1,2 *}$}

\author{
Group of Biochemistry and Cell Signaling in Nitric Oxide, Department of Experimental Biology, Area of Biochemistry and Molecular Biology, University of Jaén, \\ Jaén, Spain \\ 2 Department of Experimental Biology, Center for Advanced Studies in Olive Grove and Olive Oils, University of Jaén, Jaén, Spain \\ ${ }^{3}$ Group of Antioxidants, Free Radicals and Nitric Oxide in Biotechnology, Food and Agriculture, Department of Biochemistry, Cellular and Molecular Biology of \\ Plants, Estación Experimental del Zaidín, Consejo Superior de Investigaciones Científicas, Granada, Spain
}

\section{Edited by:}

Zhulong Chan, Chinese Academy of Sciences, China

\section{Reviewed by:}

Pengcheng Wang, Purdue

University, China

Tao Hu, Chinese Academy of

Sciences, China

\section{${ }^{*}$ Correspondence:}

Juan B. Barroso, Department of

Experimental Biology, Area of

Biochemistry and Molecular Biology,

University of Jaén, Campus Las

Lagunillas s/n, Jaén 23071, Spain

e-mail: jbarroso@ujaen.es
Linolenic acid (Ln) released from chloroplast membrane galactolipids is a precursor of the phytohormone jasmonic acid (JA). The involvement of this hormone in different plant biological processes, such as responses to biotic stress conditions, has been extensively studied. However, the role of $L n$ in the regulation of gene expression during abiotic stress situations mediated by cellular redox changes and/or by oxidative stress processes remains poorly understood. An RNA-seq approach has increased our knowledge of the interplay among Ln, oxidative stress and ROS signaling that mediates abiotic stress conditions. Transcriptome analysis with the aid of RNA-seq in the absence of oxidative stress revealed that the incubation of Arabidopsis thaliana cell suspension cultures (ACSC) with Ln resulted in the modulation of 7525 genes, of which 3034 genes had a 2-fold-change, being 533 up- and 2501 down-regulated genes, respectively. Thus, RNA-seq data analysis showed that an important set of these genes were associated with the jasmonic acid biosynthetic pathway including lypoxygenases ( $L O X_{S}$ ) and Allene oxide cyclases (AOCs). In addition, several transcription factor families involved in the response to biotic stress conditions (pathogen attacks or herbivore feeding), such as WRKY, JAZ, $M Y C$, and $L R R$ were also modified in response to Ln. However, this study also shows that Ln has the capacity to modulate the expression of genes involved in the response to abiotic stress conditions, particularly those mediated by ROS signaling. In this regard, we were able to identify new targets such as galactinol synthase 1 (GOLS1), methionine sulfoxide reductase $(M S R)$ and alkenal reductase in ACSC. It is therefore possible to suggest that, in the absence of any oxidative stress, $L n$ is capable of modulating new sets of genes involved in the signaling mechanism mediated by additional abiotic stresses (salinity, UV and high light intensity) and especially in stresses mediated by ROS.

Keywords: linolenic acid, Arabidopsis, massively parallel sequencing, RNA-seq, methionine sulfoxide reductase, oxidative stress, ROS signaling

\section{INTRODUCTION}

The poly-unsaturated fatty acid $\alpha$-Linolenic acid (Ln), with an 18 -carbon chain and three cis double bonds, is an essential omega-3 fatty acid and organic compound found in seeds such as flaxseed, chia, soybean and various vegetable oils.

Ln, which can be released from several complex fatty acids mainly located in the membranes of organelles such as chloroplast is a precursor of the jasmonic acid (JA) phytohormone and, consequently, of the oxylipin pathway. It is generally accepted that phospholipase $1\left(\mathrm{PLA}_{1}\right)$ is able to release Ln from the sn1 position of galactolipids which is responsible for generating the JA substrate. The oxygenation of Ln is the initial step in JA biosynthesis which is carried out by plastid-located lipoxygenases (LOXs) at $\mathrm{C}-13$ and is followed by the dehydration of 13-hydroperoxy-octadecatrienoic acid caused by allene oxide synthase (AOS). The unstable epoxide generated is then cyclized stereospecifically and converted into 12-oxo-phytodienoic acid (OPDA) by allene oxide cyclase (AOC) followed by the reduction of OPDA to 3-oxo-2-(2'(Z)-pentenyl)-cyclopentane-1 octanoic acid by the Arabidopsis OPDA reductase (OPR3). Finally, the subsequent shortening of the carboxylic acid side chain is caused by the fatty acid $\beta$-oxidation machinery and is initiated by Acyl-CoA-oxydase1 (ACX1) (Wasternack and Hause, 2013; Wasternack, 2014b).

The regulation of JA biosynthesis is determined by a positive feedback loop, substrate availability and tissue specificity (Wasternack, 2007). This phytohormone mediates several processes during plant growth such as male and female organ as 
well as embryo development, sex determination in maize, seed germination, seedling development, root growth, gravitropism, trichome and tuber formation, leaf movement and leaf senescence. Other processes mediated by JA include plant responses to desiccation, ozone, UV, osmotic, cold and light stresses as well as secondary metabolite formation and seasonal and circadian rhythm adaptations (Wasternack, 2014a).

Previously, the development of microarray technology enabled researchers to carry out large-scale studies and to analyze the response of thousands of genes in a single experiment. This technology has been used to analyze methyl-jasmonate-responsive genes in Arabidopsis thaliana cells (Pauwels et al., 2008) and to evaluate the role of different phytohormone-induced transcription factors in differential responses to damage caused by two different insect herbivores (Rehrig et al., 2014). These studies indicate that the application of jasmonate-derived molecules at an early stage prompted the expression of genes from the JA biosynthetic pathway and a later response in which a cellular metabolism is reprogrammed and cell cycle progression takes place, with the addition of a different response depending on the herbivore involved. Although most of these studies use jasmonate-derived molecules, to our knowledge, Ln, the principal component that engenders this pathway, has not been studied. Thus, jasmonateresponsive genes in $A$. thaliana have been identified with the aid of medium- and large-scale transcriptomic analyses using microarray technology (Pauwels et al., 2008). In recent years, new high-throughput sequencing methods, called massively parallel sequencing or RNA-seq, have emerged as a useful tool that could replace and improve upon existing methods given their advantages as compared to array-based methods (Wilhelm and Landry, 2009; Van Verk et al., 2013); (i) they do not depend on prior descriptions of the genomic sequence of the target species, making it easier to carry out gene expression studies of complex organisms; (ii) RNA-seq technology not only enables gene expression to be quantified but also facilitates the simultaneous identification of different isoforms, promoters, transcription start sites (TSS) and alternative splicing sites; (iii) RNA-seq is capable of detecting low-abundance transcripts; (iv) RNA-seq output is at the theoretical maximum of base pair resolution. As a result, RNA-seq data for higher plants have very recently started to be compiled (Lee et al., 2010; Li et al., 2012; De Cremer et al., 2013; Donà et al., 2013; Postnikova et al., 2013; Van Moerkercke et al., 2013).

The aim of the present study is to deepen our knowledge of how the linolenic acid precursor of jasmonic acid mediates new plant defense signaling pathways. The data indicate that Ln modulates the gene expression in the response to both biotic and abiotic stresses, which are especially mediated by reactive oxygen species (ROS). In this regard, a large-scale gene expression analysis has been carried out using paired-end RNA-seq technology developed by Illumina and is the first study of Arabidopsis to use this technique in order to increase our understanding of the Lnsignaling mechanism in the ROS metabolism. This technology has enabled us to gain an insight into transcriptional information and biological pathways that respond to Ln signaling which could not previously be identified by array-based methods applied to plants.

\section{MATERIALS AND METHODS PLANT MATERIAL, GROWTH CONDITIONS, AND TREATMENTS}

A. thaliana cell suspension cultures (ACSC) were maintained in $200 \mathrm{ml}$ liquid growth medium (Jouanneau and Péaud-Lenoël, 1967; Axelos et al., 1992) by gentle agitation at $120 \mathrm{rpm}$ and $24^{\circ} \mathrm{C}$ under continuous $50 \mu \mathrm{E} \mathrm{m}^{-2} \mathrm{~s}^{-1}$ PAR (photosynthetically active radiation) illumination in an incubator shaker (Multitron Standard model, Infors HT). Cells were subcultured with a 1/20th dilution every 7 days. To analyze the involvement of linolenic acid (Ln) in the mechanism of gene expression regulation, 9-dayold ACSC were incubated with $1 \mathrm{mM}$ Ln (which is equivalent to $10 \mu \mathrm{mol} \mathrm{Ln/g} \mathrm{FW)} \mathrm{and} \mathrm{methanol} \mathrm{(a} \mathrm{fatty} \mathrm{acid} \mathrm{vehicle)} \mathrm{and}$ distilled water as controls. The treatments were applied under non-stress conditions. Due to ACSC growth in liquid medium, first step was the extraction by vacuum of liquid and pellets of cells were then harvested and used for RNA isolation. Samples were designated as control $(\mathrm{C})$, vehicle $(\mathrm{MeOH})$ and linolenic acid (Ln) ACSC.

\section{RNA SAMPLE PREPARATION AND HIGH-THROUGHPUT SEOUENCING}

Total RNA from pooled ACSC was obtained using Trizol Reagent (Gibco-BRL), as described in the manufacturer's manual. RNA was then purified using a Spectrum Plant Total RNA kit (SigmaAldrich, St Louis, MO, USA) according to the manufacturer's instructions. Any DNA contamination was removed by DNase I treatment on column (Roche, Basel, Switzerland). The RNA quality tests and concentrations were determined using a NanoVue ${ }^{\mathrm{TM}}$ Plus Spectrophotometer (GE Healthcare). RNA was pooled from each sample and complementary DNA (cDNA) libraries and sequencing in an Illumina HiSeq 1000 sequencer were generated by GeneSystems (Valencia, Spain). Two replicates of each sample were sequenced on different lanes in the flow cell.

\section{BIOINFORMATIC ANALYSIS}

Quality control of sequencing was carried out using FastQC software (V0.10.1). Gene-expression was studied using DNAStar (ArrayStar 4) Qseq software for RNA-seq analysis (www.dnastar. com) with the TAIR10 database as template. For mapping purposes, we used the $k$-mer $=63$ and $95 \%$ of matches parameters and the reads per kilobase per million mapped reads (RPKM) default normalization method. The gene ontology (GO) terms were loaded in the Blast2GO suite V.2.7.2 (Conesa et al., 2005; Conesa and Götz, 2008) in order to statistically analyze GO-term enrichment. Blast2GO integrated the Gossip package for statistical assessment of differences in GO-term abundance between two sets of sequences (Blüthgen et al., 2004). This package uses Fisher's exact test and corrects for multiple testing. A one-tailed Fisher's exact test was carried out using a false discovery rate (FDR) with a filter value of $<0.01$. Blast2GO returns GO terms over-represented at a specified significance value (Conesa and Götz, 2008). The results were saved in a Microsoft Excel datasheet, and charts were generated.

For functional annotation purposes, genes studied showing significant expression-level changes in response to linolenic treatment were analyzed using DAVID (Dennis et al., 2003; Da Wei Huang and Lempicki, 2008) and TAIR (http://www.arabidopsis. org/tools/bulk/go/index.jsp) databases. 


\section{MEASUREMENT OF THIOBARBITURIC ACID REACTIVE SUBSTANCES (TBARS)}

TBARS were measured using the method described above (Stewart and Bewley, 1980) involving the spectrophotometric measurement of the pink pigment produced by the reaction of thiobarbituric acid (TBA) with malondialdehyde (MDA) and other secondary lipid peroxidation products. The evaluation of absorbance at $532 \mathrm{~nm}$ gives a measure of the extent of lipid degradation. ACSC treated with $1 \mathrm{mM}$ Ln were homogenized with liquid nitrogen to obtain a fine powder and were mixed with a solution containing $918 \mathrm{mM}$ trichloroacetic acid, $25.6 \mathrm{mM}$ thiobarbituric acid and $250 \mathrm{mM} \mathrm{HCl}$ (ratio 1/5; w/v). The mixture was heated at $85^{\circ} \mathrm{C}$ for $30 \mathrm{~min}$, the reaction was stopped by abrupt placement in an ice-bath and the cooled mixture was centrifuged at $10000 \mathrm{~g}$ for $10 \mathrm{~min}$. Absorbance at 532 and $600 \mathrm{~nm}$ was measured and, in order to correct for background absorption, absorbance values at $600 \mathrm{~nm}$ were subtracted from those at $532 \mathrm{~nm}$, with the latter representing the absorption maximum of the TBA: MDA adduct. A molar extinction coefficient of $156,000\left(1.5610^{5} \mathrm{M}^{-1} \mathrm{~cm}^{-1}\right)$ was used. All determinations were performed in triplicate and expressed in $\mathrm{pmol} \mathrm{MDA} / \mathrm{g}$ fresh weight.

\section{SPECTROPHOTOMETRIC DETERMINATION OF HYDROGEN PEROXIDE $\left(\mathrm{H}_{2} \mathbf{O}_{2}\right)$}

Hydrogen peroxide $\left(\mathrm{H}_{2} \mathrm{O}_{2}\right)$ content was measured as described by Jiang et al. (1990). Samples were incubated with a solution composed of $500 \mu \mathrm{M}$ ammonium ferrous sulfate, $50 \mathrm{mM}$ sulphuric acid, $200 \mu \mathrm{M}$ xylenol orange and $200 \mathrm{mM}$ sorbitol (ratio 1/2.5; $\mathrm{w} / \mathrm{v}$ ) in the dark for $45 \mathrm{~min}$ and then centrifuged at $2400 \mathrm{~g}$ for $10 \mathrm{~min}$. Absorbance at $560 \mathrm{~nm}$ was measured and $\mathrm{H}_{2} \mathrm{O}_{2}$ concentration was estimated as $\mathrm{H}_{2} \mathrm{O}_{2}$ equivalent using a standard curve determined with commercial $\mathrm{H}_{2} \mathrm{O}_{2}$.

\section{DETERMINATION OF PROTEIN CARBONYL CONTENT}

All procedures were performed at $0-4^{\circ} \mathrm{C}$. Cell cultures were ground to a powder using a mortar with liquid nitrogen and were suspended in $100 \mathrm{mM}$ Tris- $\mathrm{HCl}$ buffer, $\mathrm{pH} 7.5$ (ratio 1/2; w/v) containing 5\% (w/v) sucrose, 7\% (w/v) PVPP, 0.05\% Triton $\mathrm{x}-$ 100, 0.1 mM EDTA, $1 \mathrm{mM}$ PMSF and a commercial cocktail of protease inhibitors containing AEBSF, 1,10-phenantroline, pepstatine A, leupeptine, bestatine and E-64 (Sigma, St. Louis, MO, USA). Homogenates were filtered through one layer of Miracloth (Calbiochem, San Diego, CA, USA) and centrifuged at $3000 \mathrm{~g}$ for $10 \mathrm{~min}$. A $2 \%(\mathrm{w} / \mathrm{v})$ streptomycin sulfate solution was added to each sample in order to precipitate nucleic acids, which may cause an erroneously high estimate of protein-bound carbonyl, agitated for $20 \mathrm{~min}$ and then centrifuged at $2000 \mathrm{~g}$ for $10 \mathrm{~min}$. A $10 \mathrm{mM}$ DNPH solution in $2 \mathrm{~N} \mathrm{HCl}$ was then added to the protein pellet of each sample, with $2 \mathrm{~N} \mathrm{HCl}$ only being added to corresponding sample aliquot reagent blanks. Samples were allowed to stand in the dark at room temperature for $1 \mathrm{~h}$ and were then precipitated with $20 \%(\mathrm{w} / \mathrm{v})$ TCA for $15 \mathrm{~min}$ and centrifuged at $5000 \mathrm{~g}$ for $10 \mathrm{~min}$. Protein pellets were washed three times with ethanol/ethyl acetate $(1: 1, v / v)$ to remove any free DNPH. Samples were then resuspended in $6 \mathrm{M}$ guanidine hydrochloride, dissolved in $20 \mathrm{mM}$ phosphate buffer, $\mathrm{pH} 2.3$, at $37^{\circ} \mathrm{C}$ for
15 min with vortex mixing. Carbonyl content was determined from absorbance at $370 \mathrm{~nm}$ using a molar absorption coefficient of 22,000 $\mathrm{M}^{-1} \mathrm{~cm}^{-1}$ for DNPH (Levine et al., 1990) and also by measuring protein content at $280 \mathrm{~nm}$. Simultaneously, a BSA standard curve, dissolved in $6 \mathrm{M}$ guanidine hydrochloride and incubated at $37^{\circ} \mathrm{C}$ for $15 \mathrm{~min}$, was constructed.

\section{FATTY ACID ANALYSIS OF ARABIDOPSIS THALIANA}

The Arabidopsis lipid fraction of cell suspension cultures was analyzed using a gas chromatograph (GC) (Agilent 7890A). The Meth-Prep II (Alltech Chemicals Cat. No. 18007) GC reagent was used for the transesterification of the Arabidopsis lipid fraction for gas chromatographic analysis purposes, and a standard oil mixture (Supelco ref. 18919-1AMP) was used to calibrate the gas chromatograph. Each sample was placed in a microvial and evaporated under a stream of nitrogen, the lipids were dissolved in $48 \mu \mathrm{l}$ benzene and $50 \mu \mathrm{l}$ Meth Prep II reagent was added. Following the derivatization stage, a GC/MS analysis was carried out by injecting a $1 \mu \mathrm{l}$ solution. Analyses were carried out in a 7890A GC system (Agilent, USA) equipped with an SP-2560 capillary column $(100 \mathrm{~m} \times 0.25 \mathrm{~mm} \times 0.25 \mu \mathrm{m})$ and a Quattro micro GC mass spectrometer (Waters, USA). The GC column procedure was as follows: initial temperature $140^{\circ} \mathrm{C}$, maintained for $5 \mathrm{~min}$, increased at $4^{\circ} \mathrm{C} \mathrm{min}^{-1}$ to $250^{\circ} \mathrm{C}$ with a split ratio at injector port of 1:10.

\section{QUANTITATIVE REAL-TIME REVERSE TRANSCRIPTASE-PCR (qRT-PCR)}

Total RNA from pooled of control, vehicle and linolenic acid ACSC was isolated as above, and first-strand cDNA was synthesized using the First Strand cDNA Synthesis kit (Roche) in a final volume of $20 \mu \mathrm{l}$ according to the manufacturer's instructions. Real-time PCR was performed in a CFX384 real-time PCR Detection System (Bio-Rad). Amplifications were carried out in $5 \mu \mathrm{l}$ of total volume containing $5 \mathrm{ng}$ of cDNA, $2 \mu \mathrm{M}$ of specific primers (see Supplemental Table 9) and SsoFast EvaGreen Supermix (Bio-Rad). PCR conditions used consisted of an initial denaturation at $98^{\circ} \mathrm{C}$ for $30 \mathrm{~s}$, followed by 39 cycles at $98^{\circ} \mathrm{C}, 5 \mathrm{~s}$ and $60^{\circ} \mathrm{C}, 30 \mathrm{~s}$. After cycling, melting curves of the reaction were run from $72^{\circ} \mathrm{C}$ to $82^{\circ} \mathrm{C}$. Results were normalized using Actin 12 (AT3G46520), 18S rRNA (AT2G01010), and L2 (AT2G44065) as internal controls.

\section{DATA AVAILABILITY}

The Illumina sequenced read data reported in this article have been deposited in the National Center for Biotechnology Information (NCBI) Sequence Read Archive and are available under the Accession Numbers Bioproject ID: PRJNA273982 and SRP Study Accession: SRP052987.

\section{RESULTS}

Fatty acid composition of Arabidopsis cell suspension cultures (ACSC) showed that linolenic acid ( $\mathrm{Ln}$ ) was the most abundant fatty acid, accounting for approximately 50\% of total $(0.134 \mu \mathrm{mol} \mathrm{Ln} / \mathrm{g} \mathrm{FW})$, followed by linoleic acid, with $20 \%$ of total (Supplemental Table 1), showing that these data were consistent with those obtained by Bonaventure et al. (2003). As Ln is the jasmonic acid precursor and the major fatty acid in ACSC and 
given that Ln-treatment did not cause oxidative damage in ACSC, it was therefore selected for this study.

In addition, ACSC treatment with $1 \mathrm{mM} \mathrm{Ln}$ for $1 \mathrm{~h}$ did not increase ROS content such as $\mathrm{H}_{2} \mathrm{O}_{2}$ or caused oxidative damage as lipid and protein oxidation markers such as malondialdehyde (MDA) and protein carbonyl content, respectively, were not affected (Supplemental Table 2).

\section{TRANSCRIPTOMIC ANALYSIS OF LN-RESPONSIVE GENES IN ACSC}

ACSC treated with $1 \mathrm{mM}$ Ln $(10 \mu \mathrm{mol} \mathrm{Ln} / \mathrm{g} \mathrm{FW})$ to observe a clear gene expression response due to Ln-treatment, methanol (vehicle) and distilled water (control) were harvested and used for total RNA isolation. Paired-end libraries were then prepared and sequenced as described in Material and Methods. Firstly, sequence quality was checked using the FastQC program and only reads with high quality values $(\geq Q 30)$ were entered for mapping purposes (Phred values of 30 units or more which corresponds to a sequencing error rate of $0.1 \%$ ). RNA-seq analysis using DNAstar QSeq mapped the reads to the Arabidopsis transcriptome database (TAIR10) with highly stringent parameters of kmer $=63$ and 95\% of matches.

The gene-expression profile of two ACSC groups was firstly compared, one treated with distilled water and the other with $1 \mathrm{mM}$ Ln (control vs. Ln). Importantly, to eliminate genes that respond to methanol, this comparison was filtered using vehicleresponsive genes, with control vs. vehicle comparison eliminating genes with a $1.5 \mathrm{FC}$ due to methanol, henceforth referred to as control. RNA-seq analysis showed that Ln caused significant changes $(95 \%$ of matches, $p<0.05)$ in the gene-expression levels of 8947 ACSC genes, 7525 genes with annotations and 1422 genes coding for hypothetical proteins not considered for the rest of this study. From these 7525 genes, we selected 2FC up and down Ln-responsive genes showing the modulation of 3034 genes, from which 533 were up- (Supplemental Table 7) and 2501 were down-regulated (Supplemental Table 8). Due to this large number of genes, we only show the trend for genes differentially expressed with $8 \mathrm{FC}$ up and down (Figure 1). In this sense, Figure 1A shows the scatter plot of total genes whose expression changes significantly in response to Ln. Panels $1 \mathrm{~B}$ and $1 \mathrm{C}$ represent the line plot and heat map of $8 \mathrm{FC}$ over-expressed genes and panels $1 \mathrm{D}$ and $1 \mathrm{E}$ indicate the line plot and heat map of $8 \mathrm{FC}$ repressed genes.

Functional classification of 2FC-Ln-induced genes shows that their products were mostly located in the nucleus, chloroplast and plasma membrane (Figure 2A). Furthermore, they were mostly characterized by nucleotide-, protein- and DNA/RNA-binding, transferase and hydrolase activity (Figure 2B). They were also predicted to be involved in the response to stress, biotic or abiotic stimuli and protein-metabolism processes (Figure 2C). On the other hand, the most abundant categories of 2FC-Lnrepressed genes in ACSC were also located in the nucleus, chloroplast, plasma membrane and mitochondria (Figure 2D). These genes showed hydrolase-, transferase-, nucleotide-, and proteinbinding activity (Figure 2E) and were associated with the protein metabolism, developmental processes and stress responses (Figure 2F).

On the basis of these results, we decided to carry out a more detailed analysis of biological processes involved in Ln treatments. To do this, the GO terms obtained by the analysis were loaded in Blast2GO suite V.2.7.2 to statistically analyze GO-term enrichment. The unchecked two-tail box was used to analyze only positive enrichment. The test was carried out using a filter cutoff value of FDR $<1 \mathrm{e}^{-5}$ for up-regulated genes and an FDR $<$ 0.001 for down-regulated genes. The results are shown in Figure 3

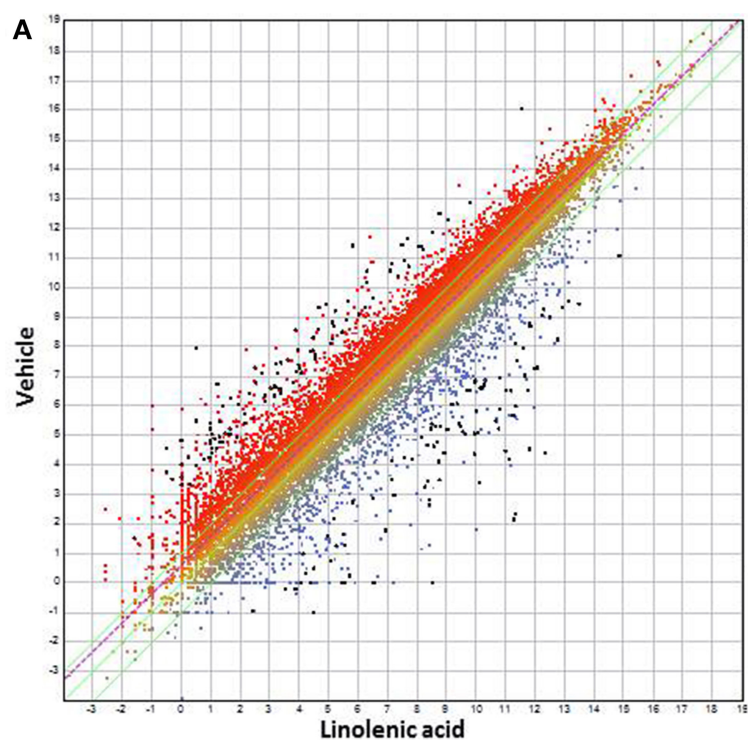

FIGURE 1 | Scatter plot, line plot and heat map for 8-fold-change genes using DNAStar software. (A) Scatter plot of total Ln-responsive genes. (B) Line plot of overexpressed genes. (C) Heat map for overexpressed genes. (D) Line plot of repressed genes. (E) Heat map for repressed genes. Distilled
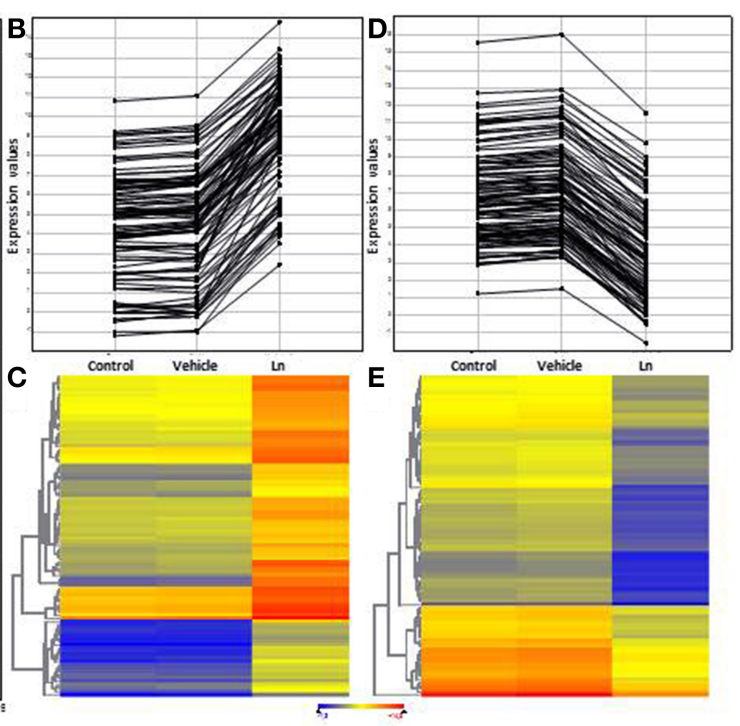

water and methanol-responsive genes were used to filter the results of $\mathrm{Ln}$ treatment. All graphs show 8-fold-change genes with 95\% significant differential expression obtained by t-student test from whole Ln-responsive genes. 


\section{UP-REGULATED}

A

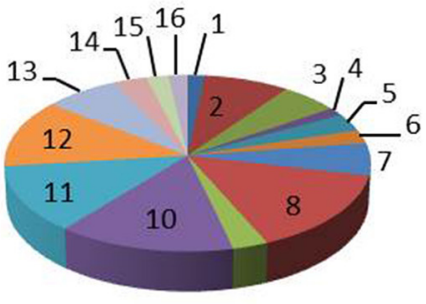

9

\section{DOWN-REGULATED}

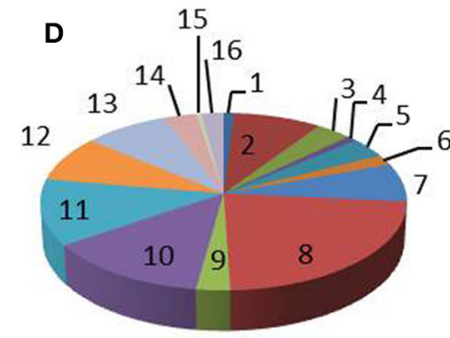

B

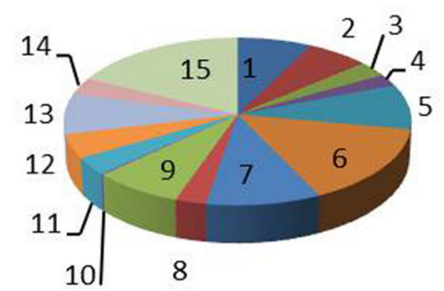

B

E

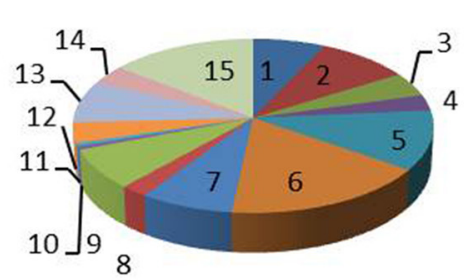

\section{Vehicle vs Ln}

C

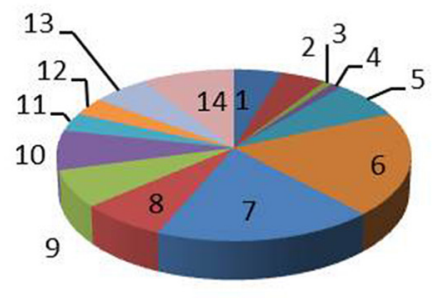

CELLULAR COMPONENT

\begin{tabular}{|c|l|c|c|}
\hline$\#$ & \multicolumn{1}{|c|}{ Go term } & A & D \\
\hline 1 & Cell wall & 1.7 & 1.0 \\
\hline 2 & Chloroplast & 8.2 & 8.5 \\
\hline 3 & Cytosol & 5.6 & 3.5 \\
\hline 4 & ER & 1.5 & 1.0 \\
\hline 5 & Extracellular & 3.2 & 3.6 \\
\hline 6 & Golgi apparatus & 2.5 & 1.9 \\
\hline 7 & Mitochondria & 5.9 & 7.0 \\
\hline 8 & Nucleus & 14.8 & 23.0 \\
\hline 9 & $\begin{array}{l}\text { Other cellular } \\
\text { components }\end{array}$ & 2.9 & 2.7 \\
\hline 10 & $\begin{array}{l}\text { Other cytoplasmic } \\
\text { components }\end{array}$ & 14.5 & 13.3 \\
\hline 11 & $\begin{array}{l}\text { Other intracellular } \\
\text { components }\end{array}$ & 12.3 & 12.1 \\
\hline 12 & Other membranes & 12.5 & 8.4 \\
\hline 13 & Plasma membrane & 7.2 & 8.2 \\
\hline 14 & Plastid & 3.2 & 3.2 \\
\hline 15 & Ribosome & 2.1 & 0.5 \\
\hline 16 & $\begin{array}{l}\text { Unknown cellular } \\
\text { components }\end{array}$ & 1.9 & 2.1 \\
\hline
\end{tabular}

MOLECULAR FUNCTION

\begin{tabular}{|c|l|c|c|}
\hline$\#$ & \multicolumn{1}{|c|}{ GO Term } & B & E \\
\hline 1 & DNA or RNA binding & 7.5 & 7.1 \\
\hline 2 & Hydrolase activity & 6.3 & 9.0 \\
\hline 3 & Kinase activity & 3.0 & 4.5 \\
\hline 4 & Nucleic acid binding & 2.3 & 3.0 \\
\hline 5 & Nucleotide binding & 8.7 & 11.1 \\
\hline 6 & Other binding & 15.0 & 17.0 \\
\hline 7 & Other enzyme activity & 9.9 & 7.7 \\
\hline 8 & $\begin{array}{l}\text { Other molecular } \\
\text { functions }\end{array}$ & 2.7 & 2.2 \\
\hline 9 & Protein binding & 7.7 & 7.5 \\
\hline 10 & $\begin{array}{l}\text { Receptor binding or } \\
\text { activity }\end{array}$ & 0.2 & 0.7 \\
\hline 11 & $\begin{array}{l}\text { Structural molecule } \\
\text { activity }\end{array}$ & 3.3 & 0.6 \\
\hline 12 & $\begin{array}{l}\text { Transcription factor } \\
\text { activity }\end{array}$ & 4.6 & 3.8 \\
\hline 13 & Transferase activity & 7.7 & 7.8 \\
\hline 14 & Transporter activity & 3.4 & 3.6 \\
\hline 15 & $\begin{array}{l}\text { Unknown molecular } \\
\text { functions }\end{array}$ & 17.7 & 14.4 \\
\hline
\end{tabular}

F

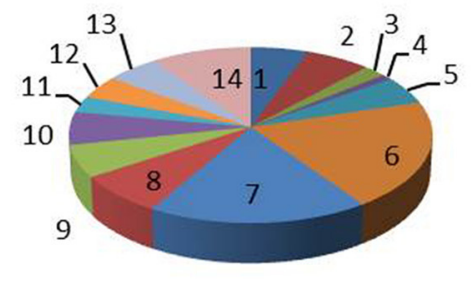

BIOLOGICAL PROCESS

\begin{tabular}{|c|l|c|c|}
\hline$\#$ & \multicolumn{1}{|c|}{ GO Term } & C & F \\
\hline 1 & $\begin{array}{l}\text { Cell organization and } \\
\text { biogenesis }\end{array}$ & 4.8 & 5.6 \\
\hline 2 & $\begin{array}{l}\text { Developmental } \\
\text { processes }\end{array}$ & 4.5 & 6.3 \\
\hline 3 & $\begin{array}{l}\text { DNA or RNA } \\
\text { metabolism }\end{array}$ & 0.9 & 2.2 \\
\hline 4 & $\begin{array}{l}\text { Electron transport or } \\
\text { energy pathways }\end{array}$ & 1.1 & 1.1 \\
\hline 5 & $\begin{array}{l}\text { Other biological } \\
\text { processes }\end{array}$ & 7.0 & 5.1 \\
\hline 6 & $\begin{array}{l}\text { Other cellular } \\
\text { processes }\end{array}$ & 19.7 & 20.0 \\
\hline 7 & $\begin{array}{l}\text { Other metabolic } \\
\text { processes }\end{array}$ & 18.6 & 18.1 \\
\hline 8 & Protein metabolism & 7.3 & 7.4 \\
\hline 9 & $\begin{array}{l}\text { Response to abiotic or } \\
\text { biotic stimulus }\end{array}$ & 7.1 & 6.0 \\
\hline 10 & Response to stress & 7.4 & 6.1 \\
\hline 11 & Signal transduction & 3.4 & 3.0 \\
\hline 12 & $\begin{array}{l}\text { Transcription, DNA- } \\
\text { dependent }\end{array}$ & 3.3 & 4.2 \\
\hline 13 & Transport & 5.6 & 5.1 \\
\hline 14 & $\begin{array}{l}\text { Unknown biological } \\
\text { processes }\end{array}$ & 9.3 & 9.8 \\
\hline
\end{tabular}

FIGURE 2 | Functional classification of Ln-responsive genes in ACSC. Genes were classified by functional categories under the following gene ontology terms: cellular component (A,D), molecular function $\mathbf{( B , E ) , ~ b i o l o g i c a l ~}$ process (C,F), up-regulated genes (A-C) and down-regulated genes (D-F). The number of genes assigned to each functional category is expressed as a percentage (\%). 
A GO enrichment UP-regulated genes

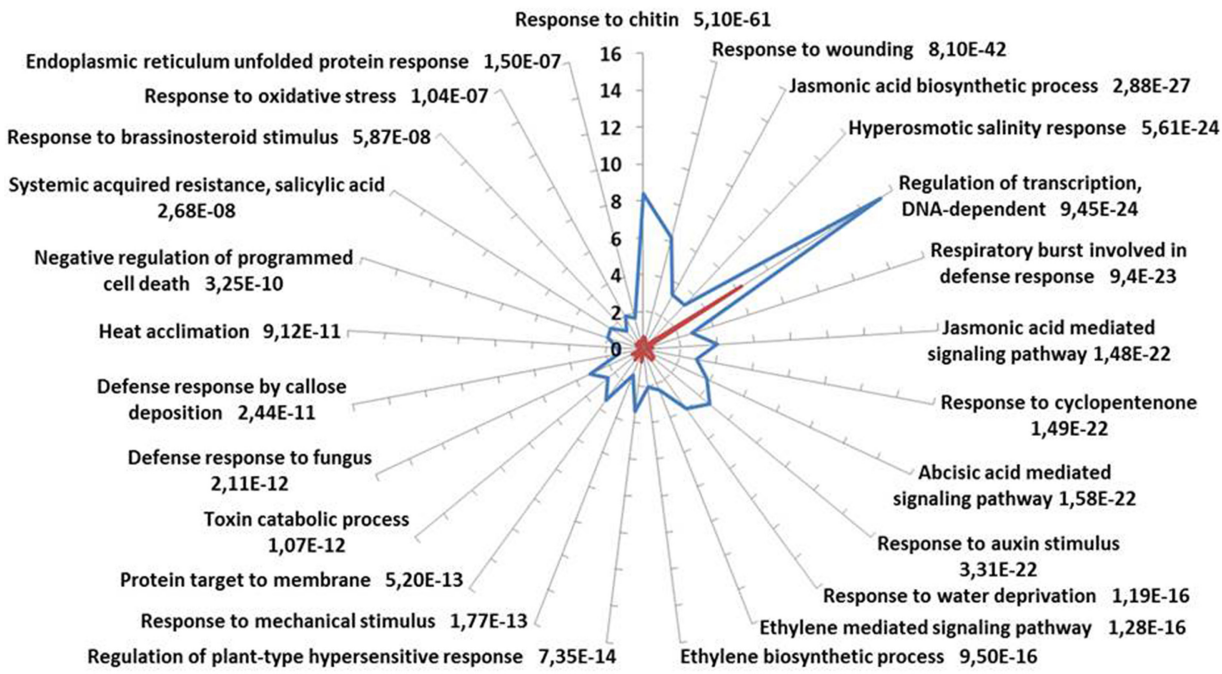

— Control ACSC — UP-regulated Ln-responsive genes

B GO enrichment DOWN-regulated genes

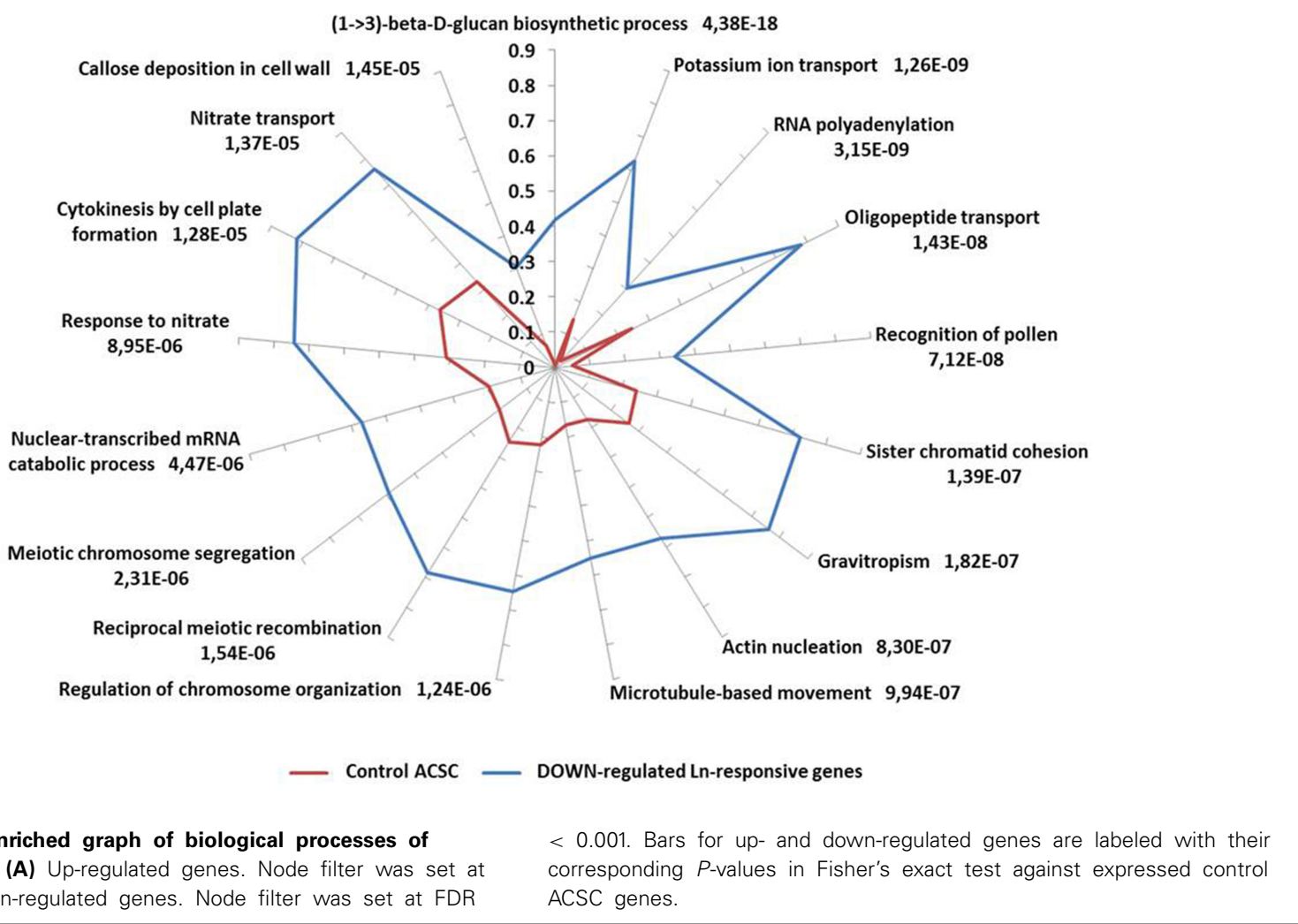

FIGURE 3 | GO-term-enriched graph of biological processes of Ln-responsive genes. (A) Up-regulated genes. Node filter was set at FDR $<1 e-5$. (B) Down-regulated genes. Node filter was set at FDR corresponding $P$-values in Fisher's exact test against expressed control ACSC genes. as the percentage of sequences annotated for each biological process GO term for both ACSC and Ln-responsive genes. Bars are labeled with their corresponding P-values in Fisher's exact test. Ln treatment of ACSC produced a significant response in the GO terms of up-regulated genes (Figure 3A). The GO terms of these genes were closely associated with biotic stress-related processes such as responses to chitin and wounding and were closely connected with biosynthesis and the JA signaling pathway. GO enrichment analysis also highlighted the over-representation of processes associated with other important phytohormones such as abscisic acid, auxin, ethylene, salicylic acid and brassinosteroids. With regard to abiotic stress, Ln treatment affected 
hyperosmotic salinity responses and heat acclimation, specifically in responses to oxidative stress through the response to hydrogen peroxide. With regard to the GO terms of down-regulated genes (Figure 3B), we found that the level of over-representation of biological processes was lower than in up-regulated genes. These processes were mostly associated with the synthesis of cell wall depicted by a (1-> 3)-beta-D-glucan biosynthetic process and callose deposition in cell wall together with the transport of potassium, oligopeptides and nitrate. Finally, mitotic- and meioticrelated processes such as sister chromatid cohesion, chromosome organization regulation, reciprocal meiotic recombination and meiotic chromosome segregation were observed.

\section{LINOLENIC ACID-RESPONSIVE GENES INVOLVED IN JASMONATE- AND BIOTIC STRESS-RELATED PROCESSES}

Ln can be released from the plasma membrane by certain lipase enzymes in response to stress (Yang et al., 2012) and, for this reason, the regulation of JA-related genes in response to Ln treatment was predicted. Several genes involved in the JA biosynthetic pathway were induced: DGL (AT1G05800), LOX4 (AT1G72520), LOX3 (AT1G17420), AOS (AT5G42650), AOC3 (AT3G25780), OPR3 (AT2G06050), and OPCL1 (AT1G20510) (see Supplemental Table 3). Furthermore, several $J A Z$ genes encoding proteins that repress JA signaling and are targeted by E3-ubiquitin ligase SCF ${ }^{C O I} 1$ for proteasome degradation in response to JA (Chico et al., 2008), were up-regulated in response to Ln treatment. Among these, RNA-seq analysis showed an increase in the transcript levels of JAZ10 (AT5G13220), JAZ6 (AT1G72450), JAZ5 (AT1G17380), JAZ9 (AT1G70700), and JAZ2 (AT1G74950). Two groups of induced transcriptional regulators of jasmonate biosynthesis and the JA-mediated signaling pathway were also detected. On the one hand, a set of activators were encoded mainly by MYC2 (AT1G32640), a (bHLHzip)-type transcription factor (TF) that directly interacts with JAZ proteins, and ORA47 (AT1G74930), the AP2/ERF protein postulated to be a positive regulator of JA biosynthesis (Pauwels et al., 2008). On the other hand, the repressors were encoded by ZAT10 (AT1G27730) and AZF2 (AT3G19580) that contain an ERFassociated amphiphilic repression domain and may act as both positive and negative regulators of plant defenses (Sakamoto et al., 2004; Mittler, 2006). In addition to the genes mentioned above, treatment of ACSC with Ln led to up-regulation of transcription factors from different families including ERF (AT4G34410, AT1G28370, AT3G15210, AT5G47220, and AT3G23240). WRKY (AT1G80840, AT5G22570), bHLH (AT2G46510) and MYB (Myeloblast) (AT3G23250, AT3G06490, AT1G74430, AT1G57560, AT4G37260, AT2G16720, AT5G67300, AT3G28910, AT4G34990, AT4G38620, and AT5G37260), mainly involved in the response to JA stimuli, and NAC (AT5G08790, AT1G01720, AT1G52890, $A T 3 G 15500$, and AT4G27410) transcription factors were also found, as previously described (Pauwels et al., 2008). On the other hand, only a few genes playing a role in JA biosynthetic processes were down-regulated. LOX5 (AT3G22400) activity in roots has been shown to facilitate green peach aphid colonization of Arabidopsis foliage (Nalam et al., 2012), indicating that the repression of this enzyme could act as an ACSC defense mechanism. Finally, in relation to the JA-mediated signaling pathway,
Ln provoked gene down-regulation of carbonic anhydrase (CA) enzymes AT5G14740 and AT3G01500 and different MYB transcription factor families (AT5G59780, AT2G36980, AT2G31180, and AT5G61420) in response to JA stimuli.

The RNA-seq study shows that Ln provoked over-expression of WRKY40 (AT1G80840) (see Supplemental Table 4) which was the most induced gene involved in defense responses, biotic stimulus and bacterium detection, negative defense response regulation and immune response regulation. WRKY40 is a pathogen-induced transcription factor that plays a positive role in JA-mediated defense (Xu et al., 2006), showing that Ln treatment launches a set of defense mechanisms against pathogen attacks. In this regard, RRTF1 (AT4G34410), involved in responding to chitin and fungus and in respiratory burst as part of a defense response, was the most up-regulated gene in the RNA-seq analysis, with an FC of 496.97. With regard to pathogen attacks, Ln treatment led to the up-regulation of BAG2 (AT5G62100) which belongs to the BAG (Bcl-2-associated athanogene) protein family and also with JAS1/JAZ10 (AT5G13220), playing a role in systemic acquired resistance (SAR), being another highly up-regulated gene. With respect to Ln-repressed genes, a broad diversity of genes was associated with a variety of cellular processes such as LRR proteins AT1G74360, AT1G51790, AT1G34420, $A T 1 G 35710$, and AT4G08850, which mainly respond to chitin and respiratory burst associated with defense responses. A large set of disease-resistant proteins were also down-regulated in response to Ln treatment, specifically in relation to defense responses and defense response signaling pathways (see Supplemental Table 4). This family of genes, of which Ln is a repressor, may be involved in responses to pathogens and abiotic stress (Rushton et al., 2010).

\section{LINOLENIC ACID-RESPONSIVE GENES INVOLVED IN ABIOTIC STRESS SITUATIONS}

The treatment of ACSC with $1 \mathrm{mM}$ Ln provoked the overexpression of genes involved in different abiotic stress situations (Figure 4). The highest induction levels $(F C=24.725$ up) were found in galactinol synthase (GOLS1, AT2G47180) which responds to heat, high light intensity, cold, salt stress and water deprivation (see Supplemental Table 5). Furthermore, different genes associated with heat responses also responded to Ln treatment such as heat stress transcription factors (AT1G52560,AT2G26150, AT4G25200, AT2G20560, AT5G56030, AT2G32120, AT1G74310, AT5G37670, AT4G21320, and $A T 1 G 16030)$ and to water deprivation as transcription factor DREB2A (AT5G05410) was highly induced. This gene has been shown to respond to dehydration and high salt stress (Liu et al., 1998). As is well known, Ln induces the jasmonate pathway involved in the response to biotic stress situations and wounding among other processes. An important set of over-expressed genes, accounting for $27.31 \%$ of the total, was involved in the response to wounding, with, as described previously, the most up-regulated gene being JAS1/JAZ10 among other JAZ proteins. $J A Z$ genes are rapidly induced by JA, suggesting the presence of a negative feedback loop to replenish the JAZ protein pool and to dampen the response to JA (Chini et al., 2007; Thines et al., 2007). A high percentage of the Ln-repressed genes were involved in the response to water deprivation and salt stress, accounting 


\section{UP-REGULATED}

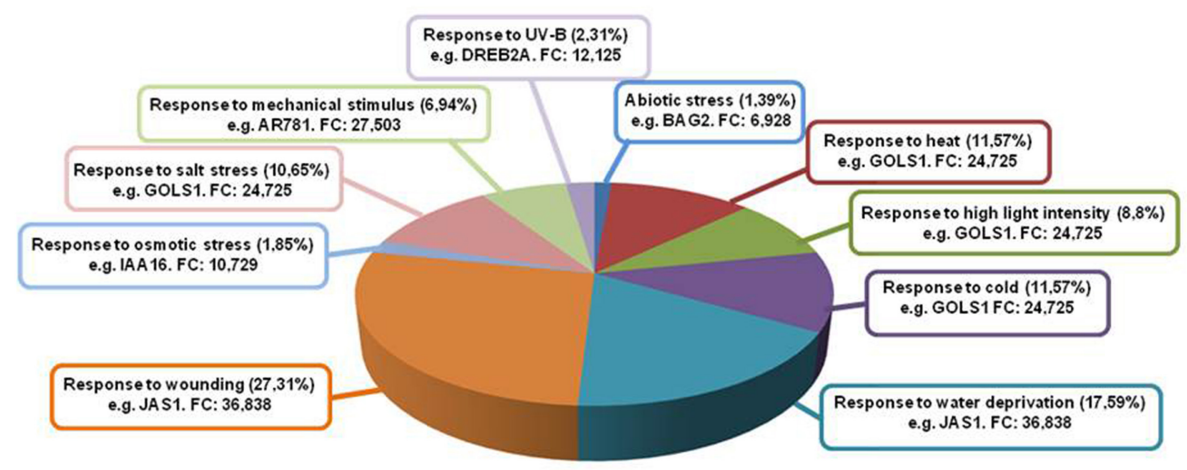

\section{DOWN-REGULATED}

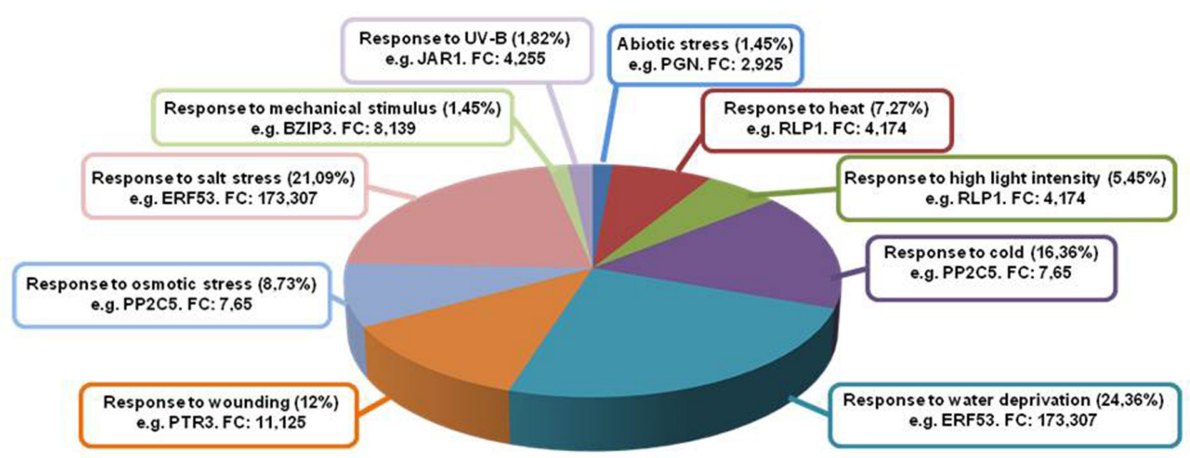

FIGURE 4 | Genes up- and down-regulated under several abiotic stress conditions. Inside each box are depicted the type of stress and most representative gene in that category with its fold change.

for 24.36 and $21.09 \%$ of down-regulated Ln-responsive genes, respectively. The highly repressed AtERF53 (AT2G20880) is associated with drought stress responses (Cheng et al., 2012), while peptide transporter 3 (AT5G46050), involved in the response to wounding, was also repressed. Finally, another important group of down-regulated genes was activated in the response to cold and osmotic stress (16.36 and 8.73\%, respectively), with the inhibition of PP2C5 (AT2G40180) acting as an MAPK phosphatase that controls MAPK levels and thus modulates innate immunity, JA and ethylene levels in Arabidopsis (Schweighofer et al., 2007).

\section{LINOLENIC ACID-RESPONSIVE GENES IN OXIDATIVE STRESS SITUATIONS}

With the aid of this (see Supplemental Table 6) transcriptomic analysis, we found a large amount of heat shock proteins (HSPs) and heat shock transcription factors (HSFs) associated with the responses to hydrogen peroxide $\left(\mathrm{H}_{2} \mathrm{O}_{2}\right)$, accounting for 25.68\% of total genes up-regulated (AT1G52560, AT2G26150, AT4G25200, AT2G20560, AT2G32120, AT1G74310, AT5G37670, $A T 4 G 21320$, and AT1G16030) (Figure 5). Recently, HsfA2 expression has been shown to be induced under different types of oxidative stress conditions such as $\mathrm{H}_{2} \mathrm{O}_{2}$ treatment (Miller and Mittler, 2006), with its overexpression producing a higher level of tolerance to several environmental stresses (Li et al., 2005). Furthermore, Ln treatment induced the expression of a set of glutathione S-transferases (AT2G29480, AT2G29470, AT2G29420, AT2G29490, AT2G29450, AT2G29460, AT2G47730, AT1G17170, and $A T 2 G 29440)$ and of methionine sulfoxide reductase $B 7$ (MSRB7, AT4G21830, FC 92.539 up). In this respect, another up-regulated enzyme associated with the detoxification of oxidized proteins was the alkenal reductase (AT5G16970). The largest percentage of up-regulated genes was associated with oxidation-reduction processes which accounted for $43.24 \%$ of total genes. Among them, we found members of 2-oxoglutarate (2OG) and Fe(II)-dependent oxygenase superfamily, as the most over-expressed genes, and a significant proportion of members of the cytochrome P450 superfamily (CYP450) (AT5G06900, AT4G19230, AT1G64950, AT2G27690, AT5G63450, AT5G47990, AT4G15393, AT5G06905, AT4G31500, and AT5G25180) encoding for fatty acid hydroxylases among others. These enzymes are capable of producing different compounds of cutin, a part of the cuticle that protects plants against various stresses (Kolattukudy, 1980). We also detected the induction of alternative oxidase 1D (AT1G32350) which plays an important role in metabolic and signaling homeostasis during abiotic and biotic stress in plants (Vanlerberghe, 2013). Finally, we also observed gene up-regulation of the monodehydroascorbate reductase 3 (MDAR3) enzyme (AT3G09940) which encodes an enzyme involved in the oxidation-reduction process. This enzyme is present in the ascorbate-glutathione cycle and is responsible for 


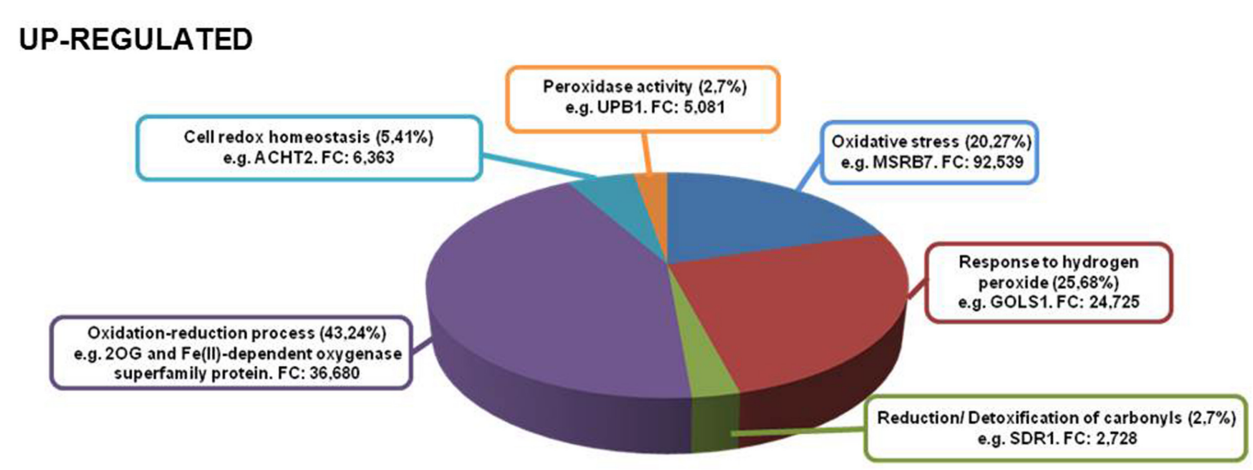

\section{DOWN-REGULATED}

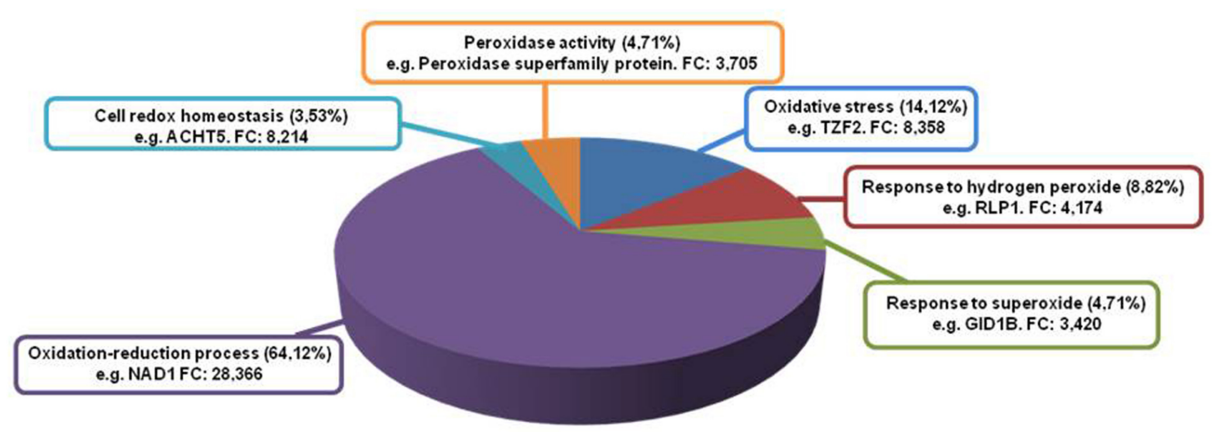

FIGURE 5 | Genes up- and down-regulated in different oxidative stress conditions. Inside each box are depicted the type of stress and most representative gene in that category with its fold change.

the regeneration of reduced ascorbate, a major antioxidant in plant cells. In this regard, an increase in the transcript levels of the peroxisomal MDAR1 gene has been observed in Pisum sativum leaves subjected to mechanical wounding (Leterrier et al., 2005). This indicates that MDAR3 gene induction in Arabidopsis caused by Ln treatment may initiate the functioning of the ascorbateglutathione cycle and thus control ROS production.

On the other hand, Ln treatment generated the downregulation of several genes involved in oxidative stress $(14.12 \%)$ such as OXS2 (AT2G41900) and OXS3 (AT5G56550). These genes have been shown to play a role in stress tolerance as they may act as chromatin remodeling factors in relation to the stress response to protect DNA or alter its transcriptional selectivity (Blanvillain et al., 2009). Finally, the most abundant down-regulated functional category was the oxidation-reduction process, accounting for $64.12 \%$ of total suppressed genes. Among these genes, the electron transport chain was inhibited, principally the components of NADH dehydrogenase complex I and cytochrome oxidase complex III (AT2G07785, AT2G07689, ATMG00650, ATMG00285, AT4G16790, ATMG01360, ATMG00513, ATCG00890, ATCG 01250, ATMG00580, ATMG00990, ATCG01090, ATMG00510, ATCG01080, ATCG01070, ATCG01100, ATCG01050, AT2G07751, and ATCG01010). It has been reported that most photosynthesisrelated genes are down-regulated after herbivore attack and may allow attacked plants to reinvest resources in other processes such as defense (Halitschke et al., 2001; Hui et al., 2003). This indicates that Ln was capable of reducing photosynthesis-related genes, possibly to counterbalance the induction of defense traits.

\section{VALIDATION OF LN-RESPONSIVE GENES BY QUANTITATIVE REAL-TIME REVERSE TRANSCRIPTION-PCR (qRT-PCR)}

To validate RNA-seq results, we randomly assigned several Lnresponsive genes to conduct the expression analysis by qRT-PCR. Figure 6 shows the comparison between the qRT-PCR and RNAseq analysis, showing that all the Ln-responsive genes tested and previously identified by RNA-seq were confirmed by qRTPCR. The results showed a positive correlation between the two approaches (with a correlation coefficient of 0.92), indicating that the RNA-seq expression analysis performed is highly reliable.

\section{DISCUSSION}

$\mathrm{LN}$ is an important molecule in plant physiology due to is the precursor of jasmonate pathway, a key component of plant defense (Wasternack and Hause, 2013). In this respect, Ln has been shown to be involved in the plant's gene responses to pathogen attacks and mechanical wounding caused by insect feeding (Wasternack, 2014a). However, little is known about the role played by Ln in gene responses to other abiotic stress situations and specifically those mediated by genes which regulate the cellular redox state and/or mediated by an oxidative stress. With the aid of RNA-seq technology, we have analyzed the transcriptional effect of Ln on ACSC by using a Ln treatment which does not provoke oxidative stress, thus enabling new gene sets involved in ROS cross-talk signaling to be identified.

Our findings indicate that $\mathrm{Ln}$ is associated with the plant's response to different abiotic stress conditions including hyperosmotic salinity and heat acclimation. Finally, one of the 


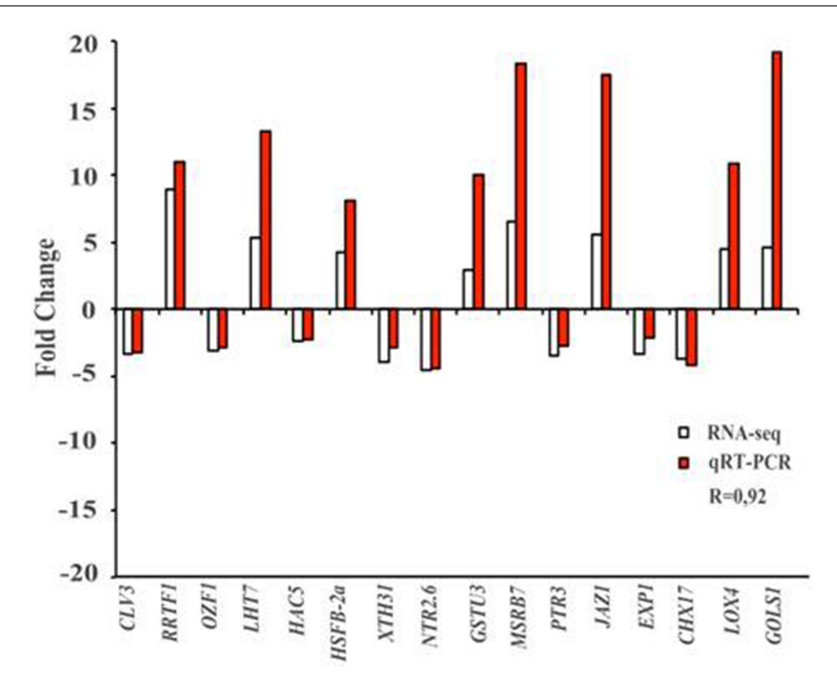

FIGURE 6 | qRT-PCR validation of RNA-seq results. Sixteen genes identified previously as Ln-responsive genes by RNA-seq (white bar) in ACSC were randomly selected to analyze, by qRT-PCR the differential expression changes (red bars). Comparison of fold change of RNA-seq and qRT-PCR showed a correlation coefficient of 0.92, indicating that RNA-seq results were reliable. Results were average of two independent samples in triplicate. Standard deviations were less than $5 \%$ in all cases. NRT2.6 (AT3G45060), Arabidopsis thaliana high affinity nitrate transporter 2.6; XTH31 (AT3G44990), Arabidopsis thaliana xyloglucan endotransglycosylase/hydrolase 31; CHX17 (AT4G23700), Arabidopsis thaliana cation/H(+) antiporter 17; PTR3 (AT5G46050), Arabidopsis thaliana putative peptide transporter protein 3; CLV3 (AT2G27250), Arabidopsis thaliana protein CLAVATA 3; OZF1 (AT2G19810), Arabidopsis thaliana Oxidation-related Zinc Finger protein 1; HAC5 (AT3G12980), Arabidopsis thaliana histone acetyltransferase 5; JAZ1 (AT1G19180), Arabidopsis thaliana jasmonate-zim-domain protein 1; LHT7 (AT4G35180), Arabidopsis thaliana LYS/HIS transporter 7; GOLS1 (AT2G47180), Arabidopsis thaliana galactinol synthase 1; HSFB-2a (AT5G62020), Arabidopsis thaliana heat stress transcription factor B-2a; GSTU3 (AT2G29470), Arabidopsis thaliana glutathione S-transferase tau 3; EXP1 (AT1G69530), Arabidopsis thaliana Alpha-Expansin protein 1; MSRB7 (AT4G21830), Arabidopsis thaliana methionine sulfoxide reductase B7; LOX4 (AT1G72520), Arabidopsis thaliana lipoxygenase 4; RRTF1 (AT4G34410), Arabidopsis thaliana redox responsive transcription factor.

most interesting processes we observed was the response to oxidative stress which led us to analyze the interaction between Ln and signaling mediated by oxidative stress-related processes, about which very little is known.

\section{LINOLENIC ACID REGULATES BIOSYNTHESIS AND SIGNALING OF JASMONATES IN ACSC. INVOLVEMENT OF LINOLENIC ACID IN BIOTIC STRESS SITUATIONS}

Ln treatment provoked the over-expression of several genes associated with jasmonate-biosynthetic processes, including lipoxygenases which constitute the first step in the formation of these molecules (Wasternack, 2014b). This phenomenon is probably due to an increase in JA levels after Ln treatment followed by a self-activation stage in JA biosynthesis that has been reported extensively in the literature (Wasternack, 2007). In addition, the application of Ln to ACSC resulted in the up-regulation of ERF1 (AT3G23240) which acts downstream of the intersection between ethylene and jasmonate pathways. It has also been suggested that this gene is a key element in the integration of both signals for regulating defense response genes (Lorenzo et al., 2003). We also observed an increase in the number of transcripts of several transcription factor families such as WRKY, bHLH, MYB, and NAC. The over-expression of all these genes shows that polyunsaturated fatty acid Ln induces the oxylipin pathway in order to produce JA-related phytohormones and consequently all components involved in its generation and functioning. In addition, several down-regulated Ln genes active in jasmonate-related processes were detected. Carbonic anhydrase (CA) was found to be a down-regulated enzyme. In this regard, in some stress situations such as wounding and herbivore attacks, CA gene expression in wounded Capsicum annuum leaves was observed to be lower than that in control leaves. This suggests that proteins playing a role in photosynthesis are down-regulated by metabolic reconfiguration in order to maintain a balance between defense and tolerance (Mahajan et al., 2014). Furthermore, several MYB transcription factors were down-regulated. In plants, $M Y B$ genes are a large family functionally active in regulating several defense processes (Kirik et al., 1998; Stracke et al., 2001), indicating that Ln launches a mechanism capable of improving the plant's defenses in different stress situations.

The release of $\mathrm{Ln}$ from membranes in response to intracellular signaling events is a key stage in the activation of defensive genes, with phospholipases being the enzymes responsible for both basal and stimulus-induced production of JA. Phospholipase A has actually been active in wound- and systemin-induced JA formation in tomato (Narváez-Vásquez et al., 1999), while phospholipase $\mathrm{D} \alpha 1$ also promotes wound-induced accumulation of free Ln and JA in Arabidopsis (Zien et al., 2001; He et al., 2002). Elicitation of wound responses in plants appearing upon mechanical wounding (abiotic stress) or herbivore attacks (biotic stress) is one of the most prominent examples and extensively studied areas where JA/JA-Ile is involved as a signal. In this regard, RNAseq analysis enabled us to identify Ln-regulated genes which play a role in the biotic, abiotic and oxidative stress responses of ACSC. With respect to genes participating in biotic stress responses, our analysis revealed the over-expression of WRKY40 and RRTF1 transcription factors. Although the role played by RRTF1 in plant defense still needs to be rigorously tested, recent reports indicate its involvement in regulating redox homeostasis during stress, with RRTF1 expression being dependent on COI1, a key regulator of JA signaling (Khandelwal et al., 2008; Wang et al., 2008). A direct physical in vivo interaction has also been shown to exist between WRKY40 and RRTF1, indicating that this WRKY transcription factor acts as a direct transcriptional repressor of RRTF1 (Pandey et al., 2010). We also detected the up-regulation of the $B A G 2$ gene which has been identified as containing a regulator of plant programmed cell death (PCD). Given that AtBAG family members have been shown to inhibit plant PCD pathways in response to stress (Doukhanina et al., 2006), Ln may act as a promoter of cell survival and resistance to biotic stress situations. In this respect, we detected over-expression of the JAS1/JAZ10 TF which is a negative regulator of JA signaling in Arabidopsis seedlings and of disease susceptibility to Pseudomonas syringae strain DC3000 (Demianski et al., 2012). This activity is mediated 
by the JAZ10.4 alternative splice variant that lacks the Jas motif in the C-terminal and mediates interaction with COI1 and MYC2 (Moreno et al., 2013). Up-regulation of this gene may be related to the JA self-regulation mechanism which controls jasmonate over-production.

\section{LINOLENIC ACID INDUCES KEY GENES OF ENZYMES INVOLVED IN THE PLANT'S DEFENSE AGAINST ABIOTIC STRESS}

An important finding produced by RNA-seq data analysis was the regulation by Ln treatment of abiotic stress response genes. Most previous studies have focused on biotic stress responses and the oxylipin pathway following the application of JA-related molecules. Nevertheless, the role of these molecules in processes participating in abiotic stress situations, particularly in relation to oxidative stress, is not very well known. In this regard, we detected an up-regulation of the galactinol synthase enzyme (GOLS1, AT2G47180) with a FC of 24.725. GolS catalyzes the first stage in the biosynthesis of raffinose family oligosaccharides (RFOs) from UDP-galactose and also RFO-derived molecules like raffinose and stachyose which intervene in the accumulation of osmoprotectants during seed development. In this respect, galactinol synthase has been shown to play a key role in the accumulation of galactinol and raffinose under abiotic stress conditions such as drought, high salinity and cold (Taji et al., 2002). In addition to these findings, high intracellular levels of galactinol and raffinose have recently be demonstrated to correlate with increased tolerance to methylviologen (MV) treatment as well as salinity and chilling stress conditions. This suggests that these molecules may scavenge hydroxyl radicals protecting plant cells from oxidative damage caused by these stresses (Nishizawa et al., 2008). These findings indicate that Ln could mediate plant responses to abiotic stresses by inducing an important defense mechanism mediated by this galactinol synthase. It is important to note that a large percentage of up-regulated genes in response to Ln treatment encoded heat shock proteins (HSPs) or chaperones. As several different abiotic stress conditions can cause protein dysfunction, maintaining these proteins in their functional conformations and preventing the aggregation of non-native proteins are particularly important for cell survival under stress conditions. These HSPs can play a crucial role in protecting plants against stress by re-establishing the normal protein conformation and thus cellular homeostasis (Wang et al., 2004). In this regard, Ln could initiate a defense mechanism mediated by the induction of key components like these protein stabilizers involved in defending the plant against different abiotic stresses. In conclusion, Ln is capable of modulating the expression levels of different genes participating in a wide variety of abiotic processes such as drought, salinity and wounding. The Ln poly-unsaturated fatty acid is involved in other pathways not directly associated with biotic responses and also with several abiotic stress situations, indicating that it plays a very important role as a signaling mediator.

\section{LINOLENIC ACID RESPONSE AGAINST OXIDATIVE STRESS: INDUCTION OF METHIONE SULFOXIDE REDUCTASE (MSRB7) AND ALKENAL REDUCTASE}

Until now, most studies have focused on the exogenous administration of JA-related molecules such as methyl-jasmonate, which act as signaling molecules in order to induce responses to biotic stress situations like pathogen attacks and wounding induced by herbivores. For this reason, an important aim of this study has been to identify the genes and potential metabolic pathways involved in the regulation of the cellular redox state and/or mediated by an oxidative stress in response to Ln treatment under non-oxidative stress conditions. Remarkably, in this regard, we detected the over-expression of methione sulfoxide reductase B7 (MSRB7, FC 92.539). Methionine oxidation by ROS (John et al., 2001) leads to the formation of MetSO (Boschi-Muller et al., 2008) which could alter both the activity and conformation of many proteins (Dos Santos et al., 2005; Rouhier et al., 2006). This enzyme catalyzes the reduction of methionine sulfoxides back to methionine and can also repair oxidized proteins and protect against oxidative damage (Moskovitz, 2005). BegaraMorales et al. (2014) showed that MSRB7 was highly induced by S-nitrosoglutathione (GSNO), suggesting that this enzyme plays a very important role in the oxidative metabolism and specifically in nitric oxide metabolism. It is therefore important to determine whether a poly-unsaturated fatty acid such as Ln is able to induce a key gene in an enzyme involved in protection against methionine oxidation, indicating crosstalk between redox status and the nitric oxide metabolism. Another important enzyme detected by this RNA-seq analysis relating to oxidized protein detoxification was the alkenal reductase enzyme. Oxidative stress produced in some biotic/ abiotic stress situations can lead to the production of ROS which damage biomolecules such as proteins and lipids. Because linoleic and linolenic acids are sources of many short-chain carbonyls due to peroxidation, biomolecules are threatened by the toxicity of reactive compounds including $\alpha, \beta$-unsaturated carbonyls, which are involved in the pathophysiological effects associated with oxidative stress in cells and tissues (Yamauchi et al., 2011). This enzyme catalyzes the reduction of the $\alpha, \beta$-unsaturated bond of reactive carbonyls which are active in anti-oxidative plant defenses (Mano et al., 2005). Finally, we also detected the induction of various glutathione Stransferase genes and a large percentage of several members of the CYP450 superfamily. In this regard, oxidative burst, involving the rapid production of enormous amounts of ROS, is one of the first mechanisms of defense against certain biotic and abiotic stresses such as wounding, cells subjected to mechanical stress or pathogen attacks. Faced with these oxidative attacks, damaged plants initiate a series of defense mechanisms by, for example, releasing Ln from cell membranes throughout several lipases. In this sense, we observed that Ln was able to enhance the expression of MSRB7 and alkenal reductase which could repair oxidative modifications in proteins caused by the high levels of ROS generated in these stress situations. Moreover, the glutathione metabolism appears to be of crucial importance due to the large number of glutathione S-transferase genes induced. These enzymes play a crucial role in detoxification of peroxidised lipids, thus contributing to the defense response potentiated by Ln. Furthermore, the induction of genes from members of the CYP450 family generates compounds as protectors and potent elicitors of defense mechanisms (Kolattukudy, 1980; Schweizer et al., 1998). In this regard, CYP94C1 has been reported to be induced at the transcriptional level by the methyl-jasmonate 
stress hormone (Kandel et al., 2007) which corroborates the findings obtained by this RNA-seq analysis.

\section{AUTHOR CONTRIBUTIONS}

The experiments were conceived and designed by: JBB, FC, FL, $\mathrm{BS}, \mathrm{CM}$, and JCB. The experiments were performed by: CM, BS, JCB, MP, RV, FL, AF, JJ, JF, FC, and JBB. The data were analyzed by: CM, JBB, JCB, and FL. The paper was written by: CM, JBB, $\mathrm{FC}, \mathrm{FL}$, and JCB.

\section{ACKNOWLEDGMENTS}

$\mathrm{CP}$ would like to thank the University of Jaén for funding the Ph.D. fellowship. This study was supported by an ERDF grant co-financed by the Ministry of Economy and Competitiveness (projects BIO2012-33904 and RECUPERA2020) and the Junta de Andalucía (groups BIO286 and BIO192) in Spain. A. thaliana cell suspension cultures (ACSC) were kindly provided by Dr. Juan Bautista Arellano from the Institute of Natural Resources and Agrobiology (IRNASA-CSIC, Salamanca, Spain).

\section{SUPPLEMENTARY MATERIAL}

The Supplementary Material for this article can be found online at: http://www.frontiersin.org/journal/10.3389/fpls.2015.00122/ abstract

Supplemental Table 1 | Fatty acid composition of Arabidopsis thaliana cell suspension cultures (ACSC).

Supplemental Table 2 | Effect of Ln on oxidative stress markers.

Supplemental Table 3 | Ln-responsive genes involved in jasmonate-related processes.

Supplemental Table 4 | Ln-responsive genes involved in biotic stress situations.

Supplemental Table 5 | Ln-responsive genes involved in abiotic stress situations.

Supplemental Table 6 | Ln-responsive genes involved in oxidative stress conditions.

Supplemental Table 7 | 2FC-up-regulated genes by Linolenic acid-treatment.

Supplemental Table 8 | 2FC-down-regulated genes by Linolenic acid-treatment.

Supplemental Table 9 | Oligonucleotides used for qRT-PCR.

\section{REFERENCES}

Axelos, M., Curie, C., Mazzolini, L., Bardet, C., and Lescure, B. (1992). A protocol for transient gene expression in Arabidopsis thaliana protoplasts isolated from cell suspension cultures. Plant Physiol. Biochem. 30, 123-128.

Begara-Morales, J. C., Sánchez-Calvo, B., Luque, F., Leyva-Pérez, M. O., Leterrier, M., Corpas, F. J., et al. (2014). Differential transcriptomic analysis by RNAseq of GSNO-responsive genes between Arabidopsis roots and leaves. Plant Cell Physiol. 55, 1080-1095. doi: 10.1093/pcp/pcu044

Blanvillain, R., Kim, J. H., Wu, S., Lima, A., and Ow, D. W. (2009). OXIDATIVE STRESS 3 is a chromatin-associated factor involved in tolerance to heavy metals and oxidative stress. Plant J. 57, 654-665. doi: 10.1111/j.1365313X.2008.03717.x

Blüthgen, N., Brand, K., Čajavec, B., Swat, M., Herzel, H., and Beule, D. (2004). Biological profiling of gene groups utilizing Gene Ontology. Genome Inform. $16,106-115$.

Bonaventure, G., Salas, J. J., Pollard, M. R., and Ohlrogge, J. B. (2003). Disruption of the FATB gene in Arabidopsis demonstrates an essential role of saturated fatty acids in plant growth. Plant Cell 15, 1020-1033. doi: 10.1105/tpc.008946
Boschi-Muller, S., Gand, A., and Branlant, G. (2008). The methionine sulfoxide reductases: catalysis and substrate specificities. Arch. Biochem. Biophys. 474, 266-273. doi: 10.1016/j.abb.2008.02.007

Cheng, M.-C., Hsieh, E.-J., Chen, J.-H., Chen, H.-Y., and Lin, T.-P. (2012). Arabidopsis RGLG2, functioning as a RING E3 ligase, interacts with AtERF53 and negatively regulates the plant drought stress response. Plant Physiol. 158, 363-375. doi: 10.1104/pp.111.189738

Chico, J. M., Chini, A., Fonseca, S., and Solano, R. (2008). JAZ repressors set the rhythm in jasmonate signaling. Curr. Opin. Plant Biol. 11, 486-494. doi: 10.1016/j.pbi.2008.06.003

Chini, A., Fonseca, S., Fernandez, G., Adie, B., Chico, J., Lorenzo, O., et al. (2007). The JAZ family of repressors is the missing link in jasmonate signalling. Nature 448, 666-671. doi: 10.1038/nature06006

Conesa, A., and Götz, S. (2008). Blast2GO: a comprehensive suite for functional analysis in plant genomics. Int. J. Plant Genomics 2008:619832. doi: $10.1155 / 2008 / 619832$

Conesa, A., Götz, S., García-Gómez, J. M., Terol, J., Talón, M., and Robles, M. (2005). Blast2GO: a universal tool for annotation, visualization and analysis in functional genomics research. Bioinformatics 21, 3674-3676. doi: 10.1093/bioinformatics/bti610

Da Wei Huang, B. T. S., and Lempicki, R. A. (2008). Systematic and integrative analysis of large gene lists using DAVID bioinformatics resources. Nat. Protoc. 4, 44-57. doi: 10.1038/nprot.2008.211

De Cremer, K., Mathys, J., Vos, C., Froenicke, L., Michelmore, R. W., Cammue, B., et al. (2013). RNAseq-based transcriptome analysis of Lactuca sativa infected by the fungal necrotroph Botrytis cinerea. Plant Cell Environ. 36, 1992-2007. doi: $10.1111 /$ pce. 12106

Demianski, A. J., Chung, K. M., and Kunkel, B. N. (2012). Analysis of Arabidopsis JAZ gene expression during Pseudomonas syringae pathogenesis. Mol. Plant Pathol. 13, 46-57. doi: 10.1111/j.1364-3703.2011.00727.x

Dennis, G. Jr., Sherman, B. T., Hosack, D. A., Yang, J., Gao, W., Lane, H. C., et al. (2003). DAVID: database for annotation, visualization, and integrated discovery. Genome Biol. 4:P3. doi: 10.1186/gb-2003-4-5-p3

Donà, M., Confalonieri, M., Minio, A., Biggiogera, M., Buttafava, A., Raimondi, E., et al. (2013). RNA-Seq analysis discloses early senescence and nucleolar dysfunction triggered by Tdpl $\alpha$ depletion in Medicago truncatula. J. Exp. Bot. 64, 1941-1951. doi: 10.1093/jxb/ert063

Dos Santos, C. V., Cuiné, S., Rouhier, N., and Rey, P. (2005). The Arabidopsis plastidic methionine sulfoxide reductase B proteins. Sequence and activity characteristics, comparison of the expression with plastidic methionine sulfoxide reductase A, and induction by photooxidative stress. Plant Physiol. 138, 909-922. doi: 10.1104/pp.105.062430

Doukhanina, E. V., Chen, S., Van Der Zalm, E., Godzik, A., Reed, J., and Dickman, M. B. (2006). Identification and functional characterization of the BAG protein family in Arabidopsis thaliana. J. Biol. Chem. 281, 18793-18801. doi: 10.1074/jbc.M511794200

Halitschke, R., Schittko, U., Pohnert, G., Boland, W., and Baldwin, I. T. (2001). Molecular interactions between the specialist herbivoremanduca sexta (Lepidoptera, Sphingidae) and its natural host nicotiana attenuata. III. Fatty acid-amino acid conjugates in herbivore oral secretions are necessary and sufficient for herbivore-specific plant responses. Plant Physiol. 125, 711-717. doi: 10.1104/pp.125.2.711

He, Y., Fukushige, H., Hildebrand, D. F., and Gan, S. (2002). Evidence supporting a role of jasmonic acid in Arabidopsis leaf senescence. Plant Physiol. 128, 876-884. doi: 10.1104/pp.010843

Hui, D., Iqbal, J., Lehmann, K., Gase, K., Saluz, H. P., and Baldwin, I. T. (2003). Molecular Interactions between the specialist herbivoremanduca sexta (Lepidoptera, Sphingidae) and its natural host nicotiana attenuata: V. Microarray analysis and further characterization of large-scale changes in herbivore-induced mRNAs. Plant Physiol. 131, 1877-1893. doi: 10.1104/pp.102.018176

Jiang, Z.-Y., Woollard, A., and Wolff, S. P. (1990). Hydrogen peroxide production during experimental protein glycation. FEBS Lett. 268, 69-71. doi: 10.1016/0014-5793(90)80974-N

John, G. S., Brot, N., Ruan, J., Erdjument-Bromage, H., Tempst, P., Weissbach, H., et al. (2001). Peptide methionine sulfoxide reductase from Escherichia coli and Mycobacterium tuberculosis protects bacteria against oxidative damage from reactive nitrogen intermediates. Proc. Natl. Acad. Sci. U.S.A. 98, 9901-9906. doi: $10.1073 /$ pnas. 161295398 
Jouanneau, J. P., and Péaud-Lenoël, C. (1967). Growth and synthesis of proteins in cell suspensions of a kinetin dependent tobacco. Physiol. Plant. 20, 834-850. doi: 10.1111/j.1399-3054.1967.tb08371.x

Kandel, S., Sauveplane, V., Compagnon, V., Franke, R., Millet, Y., Schreiber, L., et al. (2007). Characterization of a methyl jasmonate and wounding-responsive cytochrome P450 of Arabidopsis thaliana catalyzing dicarboxylic fatty acid formation in vitro. FEBS J. 274, 5116-5127. doi: 10.1111/j.1742-4658.2007.06032.x

Khandelwal, A., Elvitigala, T., Ghosh, B., and Quatrano, R. S. (2008). Arabidopsis transcriptome reveals control circuits regulating redox homeostasis and the role of an AP2 transcription factor. Plant Physiol. 148, 2050-2058. doi: 10.1104/pp.108.128488

Kirik, V., Kölle, K., Miséra, S., and Bäumlein, H. (1998). Two novel MYB homologues with changed expression in late embryogenesis-defective Arabidopsis mutants. Plant Mol. Biol. 37, 819-827. doi: 10.1023/A:1006011002499

Kolattukudy, P. (1980). "Cutin, suberin, and waxes," in The Biochemistry of Plants, eds P. K. Stumpf and E. E. Conn (New York, NY Academic Press), 4, 571-645.

Lee, E.-K., Jin, Y.-W., Park, J. H., Yoo, Y. M., Hong, S. M., Amir, R., et al. (2010). Cultured cambial meristematic cells as a source of plant natural products. Nat. Biotechnol. 28, 1213-1217. doi: 10.1038/nbt.1693

Leterrier, M., Corpas, F. J., Barroso, J. B., Sandalio, L. M., and Luis, A. (2005). Peroxisomal monodehydroascorbate reductase. Genomic clone characterization and functional analysis under environmental stress conditions. Plant physiol. 138, 2111-2123.

Levine, R. L., Garland, D., Oliver, C. N., Amici, A., Climent, I., Lenz, A.-G., et al. (1990). Determination of carbonyl content in oxidatively modified proteins. Method. Enzymol. 186, 464. doi: 10.1016/0076-6879(90)86141-H

Li, C., Chen, Q., Gao, X., Qi, B., Chen, N., Xu, S., et al. (2005). AtHsfA2 modulates expression of stress responsive genes and enhances tolerance to heat and oxidative stress in Arabidopsis. Sci. China C. Life Sci. 48, 540-550. doi: 10.1360/062005-119

Li, S.-T., Zhang, P., Zhang, M., Fu, C.-H., Zhao, C.-F., Dong, Y.-S., et al. (2012). Transcriptional profile of Taxus chinensis cells in response to methyl jasmonate. BMC Genomics 13:295. doi: 10.1186/1471-2164-13-295

Liu, Q., Kasuga, M., Sakuma, Y., Abe, H., Miura, S., Yamaguchi-Shinozaki, K., et al. (1998). Two transcription factors, DREB1 and DREB2, with an EREBP/AP2 DNA binding domain separate two cellular signal transduction pathways in drought-and low-temperature-responsive gene expression, respectively, in Arabidopsis. Plant Cell 10, 1391-1406. doi: 10.1105/tpc.10.8.1391

Lorenzo, O., Piqueras, R., Sánchez-Serrano, J. J., and Solano, R. (2003). ETHYLENE RESPONSE FACTOR1 integrates signals from ethylene and jasmonate pathways in plant defense. Plant Cell 15, 165-178. doi: 10.1105/tpc.007468

Mahajan, N. S., Mishra, M., Tamhane, V. A., Gupta, V. S., and Giri, A. P. (2014). Stress inducible proteomic changes in Capsicum annuum leaves. Plant Physiol. Biochem. 74, 212-217. doi: 10.1016/j.plaphy.2013. 11.017

Mano, J. I., Belles-Boix, E., Babiychuk, E., Inzé, D., Torii, Y., Hiraoka, E., et al. (2005). Protection against photooxidative injury of tobacco leaves by 2 -alkenal reductase. Detoxication of lipid peroxide-derived reactive carbonyls. Plant Physiol. 139, 1773-1783. doi: 10.1104/pp.105.070391

Miller, G., and Mittler, R. (2006). Could heat shock transcription factors function as hydrogen peroxide sensors in plants? Ann Bot. 98, 279-288. doi: $10.1093 / \mathrm{aob} / \mathrm{mcl} 107$

Mittler, R. (2006). Abiotic stress, the field environment and stress combination. Trends Plant Sci. 11, 15-19. doi: 10.1016/j.tplants.2005.11.002

Moreno, J. E., Shyu, C., Campos, M. L., Patel, L. C., Chung, H. S., Yao, J., et al. (2013). Negative feedback control of jasmonate signaling by an alternative splice variant of JAZ10. Plant Physiol. 162, 1006-1017. doi: 10.1104/pp.113. 218164

Moskovitz, J. (2005). Methionine sulfoxide reductases: ubiquitous enzymes involved in antioxidant defense, protein regulation, and prevention of aging-associated diseases. Biochim. Biophys. Acta 1703, 213-219. doi: 10.1016/j.bbapap.2004.09.003

Nalam, V. J., Keeretaweep, J., Sarowar, S., and Shah, J. (2012). Root-derived oxylipins promote green peach aphid performance on Arabidopsis foliage. Plant Cell 24, 1643-1653. doi: 10.1105/tpc.111.094110

Narváez-Vásquez, J., Florin-Christensen, J., and Ryan, C. A. (1999). Positional specificity of a phospholipase A activity induced by wounding, systemin, and oligosaccharide elicitors in tomato leaves. Plant Cell 11, 2249-2260. doi: 10.1105/tpc.11.11.2249
Nishizawa, A., Yabuta, Y., and Shigeoka, S. (2008). Galactinol and raffinose constitute a novel function to protect plants from oxidative damage. Plant Physiol. 147, 1251-1263. doi: 10.1104/pp.108.122465

Pandey, S. P., Roccaro, M., Schön, M., Logemann, E., and Somssich, I. E. (2010). Transcriptional reprogramming regulated by WRKY18 and WRKY40 facilitates powdery mildew infection of Arabidopsis. Plant J. 64, 912-923. doi: 10.1111/j.1365-313X.2010.04387.x

Pauwels, L., Morreel, K., De Witte, E., Lammertyn, F., Van Montagu, M., Boerjan, W., et al. (2008). Mapping methyl jasmonate-mediated transcriptional reprogramming of metabolism and cell cycle progression in cultured Arabidopsis cells. Proc. Natl. Acad. Sci. U.S.A. 105, 1380-1385. doi: 10.1073/pnas.0711203105

Postnikova, O. A., Shao, J., and Nemchinov, L. G. (2013). Analysis of the alfalfa root transcriptome in response to salinity stress. Plant Cell Physiol. 54, 1041-1055. doi: $10.1093 / \mathrm{pcp} / \mathrm{pct} 056$

Rehrig, E. M., Appel, H. M., Jones, A. D., and Schultz, J. C. (2014). Roles for jasmonate-and ethylene-induced transcription factors in the ability of Arabidopsis to respond differentially to damage caused by two insect herbivores. Front. Plant. Sci. 5:407. doi: 10.3389/fpls.2014.00407

Rouhier, N., Dos Santos, C. V., Tarrago, L., and Rey, P. (2006). Plant methionine sulfoxide reductase A and B multigenic families. Photosynth Res. 89, 247-262. doi: 10.1007/s11120-006-9097-1

Rushton, P. J., Somssich, I. E., Ringler, P., and Shen, Q. J. (2010). WRKY transcription factors. Trends Plant Sci. 15, 247-258. doi: 10.1016/j.tplants.2010.02.006

Sakamoto, H., Maruyama, K., Sakuma, Y., Meshi, T., Iwabuchi, M., Shinozaki, K., et al. (2004). Arabidopsis Cys2/His2-type zinc-finger proteins function as transcription repressors under drought, cold, and high-salinity stress conditions. Plant Physiol. 136, 2734-2746. doi: 10.1104/pp.104.046599

Schweighofer, A., Kazanaviciute, V., Scheikl, E., Teige, M., Doczi, R., Hirt, H., et al. (2007). The PP2C-type phosphatase AP2C1, which negatively regulates MPK4 and MPK6, modulates innate immunity, jasmonic acid, and ethylene levels in Arabidopsis. Plant Cell 19, 2213-2224. doi: 10.1105/tpc.106.049585

Schweizer, P., Buchala, A., Dudler, R., and Métraux, J. P. (1998). Induced systemic resistance in wounded rice plants. Plant J. 14, 475-481. doi: 10.1046/j.1365313X.1998.00141.x

Stewart, R. R., and Bewley, J. D. (1980). Lipid peroxidation associated with accelerated aging of soybean axes. Plant Physiol. 65, 245-248. doi: 10.1104/pp.65.2.245

Stracke, R., Werber, M., and Weisshaar, B. (2001). The R2R3-MYB gene family in Arabidopsis thaliana. Curr. Opin. Plant Biol. 4, 447-456. doi: 10.1016/S13695266(00)00199-0

Taji, T., Ohsumi, C., Iuchi, S., Seki, M., Kasuga, M., Kobayashi, M., et al. (2002). Important roles of drought-and cold-inducible genes for galactinol synthase in stress tolerance in Arabidopsis thaliana. Plant J. 29, 417-426. doi: 10.1046/j.0960-7412.2001.01227.x

Thines, B., Katsir, L., Melotto, M., Niu, Y., Mandaokar, A., Liu, G., et al. (2007). JAZ repressor proteins are targets of the SCFCOI1 complex during jasmonate signalling. Nature 448, 661-665. doi: 10.1038/nature05960

Vanlerberghe, G. C. (2013). Alternative oxidase: a mitochondrial respiratory pathway to maintain metabolic and signaling homeostasis during abiotic and biotic stress in plants. Int. J. Mol. Sci. 14, 6805-6847. doi: 10.3390/ijms14046805

Van Moerkercke, A., Fabris, M., Pollier, J., Baart, G. J., Rombauts, S., Hasnain, G., et al. (2013). CathaCyc, a metabolic pathway database built from Catharanthus roseus RNA-Seq data. Plant Cell Physiol. 54, 673-685. doi: 10.1093/pcp/pct039

Van Verk, M. C., Hickman, R., Pieterse, C. M., and Van Wees, S. (2013). RNA-Seq: revelation of the messengers. Trends Plant Sci. 18, 175-179. doi: 10.1016/j.tplants.2013.02.001

Wang, W., Vinocur, B., Shoseyov, O., and Altman, A. (2004). Role of plant heatshock proteins and molecular chaperones in the abiotic stress response. Trends Plant Sci. 9, 244-252. doi: 10.1016/j.tplants.2004.03.006

Wang, Z., Cao, G., Wang, X., Miao, J., Liu, X., Chen, Z., et al. (2008). Identification and characterization of COI1-dependent transcription factor genes involved in JA-mediated response to wounding in Arabidopsis plants. Plant Cell Rep. 27, 125-135. doi: 10.1007/s00299-007-0410-z

Wasternack, C. (2007). Jasmonates: an update on biosynthesis, signal transduction and action in plant stress response, growth and development. Ann. Bot. 100, 681-697. doi: 10.1093/aob/mcm079

Wasternack, C. (2014a). Action of jasmonates in plant stress responses and development-applied aspects. Biotechnol. Adv. 32, 31-39. doi: 10.1016/j.biotechadv.2013.09.009 
Wasternack, C. (2014b). Perception, signaling and cross-talk of jasmonates and the seminal contributions of the Daoxin Xie's lab and the Chuanyou Li's lab. Plant Cell Rep. 33, 707-718. doi: 10.1007/s00299-014-1608-5

Wasternack, C., and Hause, B. (2013). Jasmonates: biosynthesis, perception, signal transduction and action in plant stress response, growth and development. An update to the 2007 review in Annals of Botany. Ann. Bot. 111, 1021-1058. doi: $10.1093 / \mathrm{aob} / \mathrm{mct} 067$

Wilhelm, B. T., and Landry, J.-R. (2009). RNA-Seq-quantitative measurement of expression through massively parallel RNA-sequencing. Methods 48, 249-257. doi: 10.1016/j.ymeth.2009.03.016

Xu, X., Chen, C., Fan, B., and Chen, Z. (2006). Physical and functional interactions between pathogen-induced Arabidopsis WRKY18, WRKY40, and WRKY60 transcription factors. Plant Cell 18, 1310-1326. doi: 10.1105/tpc.105.0 37523

Yamauchi, Y., Hasegawa, A., Taninaka, A., Mizutani, M., and Sugimoto, Y. (2011). NADPH-dependent reductases involved in the detoxification of reactive carbonyls in plants. J. Biol. Chem. 286, 6999-7009. doi: 10.1074/jbc.M110.202226

Yang, W.-Y., Zheng, Y., Bahn, S. C., Pan, X.-Q., Li, M.-Y., Vu, H. S., et al. (2012). The patatin-containing phospholipase A pPLAII $\alpha$ modulates oxylipin formation and water loss in Arabidopsis thaliana. Mol. Plant 5, 452-460. doi: $10.1093 / \mathrm{mp} / \mathrm{ssr} 118$

Zien, C. A., Wang, C., Wang, X., and Welti, R. (2001). In vivo substrates and the contribution of the common phospholipase $\mathrm{D}, \mathrm{PLD} \alpha$, to wound-induced metabolism of lipids in Arabidopsis. Biochim. Biophys. Acta 1530, 236-248. doi: 10.1016/S1388-1981(01)00091-9

Conflict of Interest Statement: The authors declare that the research was conducted in the absence of any commercial or financial relationships that could be construed as a potential conflict of interest.

Received: 18 December 2014; accepted: 14 February 2015; published online: 17 March 2015.

Citation: Mata-Pérez C, Sánchez-Calvo B, Begara-Morales JC, Luque F, Jiménez-Ruiz J, Padilla MN, Fierro-Risco J, Valderrama R, Fernández-Ocaña A, Corpas FJ and Barroso JB (2015) Transcriptomic profiling of linolenic acid-responsive genes in ROS signaling from RNA-seq data in Arabidopsis. Front. Plant Sci. 6:122. doi: 10.3389/fpls. 2015.00122

This article was submitted to Plant Physiology, a section of the journal Frontiers in Plant Science.

Copyright (C) 2015 Mata-Pérez, Sánchez-Calvo, Begara-Morales, Luque, JiménezRuiz, Padilla, Fierro-Risco, Valderrama, Fernández-Ocaña, Corpas and Barroso. This is an open-access article distributed under the terms of the Creative Commons Attribution License (CC BY). The use, distribution or reproduction in other forums is permitted, provided the original author(s) or licensor are credited and that the original publication in this journal is cited, in accordance with accepted academic practice. No use, distribution or reproduction is permitted which does not comply with these terms. 